\title{
Good Intentions: remembering through framing photographs in English homes
}

Family photographs demand of us that they be treated right. They seem ubiquitous in modern life, spread throughout the home. They are also enjoyable. Yet these everyday casual objects are nonetheless demanding. For some reason, photographs should not be thrown away. They are given and received, transmitted hand to hand and home to home, but rarely disposed of. In this paper, we investigate the importance of the framing of photographs rather than their content to this sense of obligation. We suggest that the range of ways of materially contextualising photos (which we call 'framing') in the home map out a family's collective intention to share memories in future with assorted relatives, friends and acquaintances, and to do so in a socially appropriate way. The framing of photographs helps make manifest what Gell might call a "network of intentionalities" (1999 p163). An appropriately-framed photograph seems somehow Good, denoting a moral home which neither isolates itself, nor imposes on others, but shares rightly. Remembering with appropriately-framed photographs means materialising the intention to share memories with others at a future date. As the digital revolution develops, photographic practices are changing (Frohlich 2004). Even since our fieldwork was conducted, a new generation of mobile phones is revolutionising the sharing of images and as technological developments advance, so does the need to understand the social dynamics surrounding photographs.

Contemporary discussions of photographs in anthropology have built on earlier treatments of their aesthetics and technological aspects, and moved towards the dialogues between photographs, social action and personhood. Susan Sontag wrote that photography "makes reality atomic, manageable and opaque" (1977, p23), illustrating how it appears to capture memory and make it material. Stewart (1984) argues that such material souvenirs come in time to be more significant than the fleeting events they commemorate. Over time, she suggests, the object comes to be seen as a point of origin of experience and memory, more so than the event itself. Other more recent investigations which focus on the subtle ways photographs can materialise memories of the past include Hirsch (1997), Ruby (1995) and Kuhn (1995). 
Yet these objects are surrounded by relationships and social processes. A seminal work in this direction on how photographs are culturally and socially embedded is Pinney's (1997) work on India, which has fed into the rich recent work on how art, technology and personhood interact, by Gell (1998) and Strathern (1999). Such considerations have enriched and given fresh impetus to ethnographies of photographs, their materiality and substance, not only their visuality (Edwards and Hart 2004, Edwards 2001). The attention of these studies to a processual viewpoint on materiality and sociality can appear to have a certain circularity, in so much as certain photographs are for example family photographs because they are shared, and the family is constituted by, among other things, the sharing of these photographs. Rather than ask questions about What a family photograph is, it becomes more interesting to investigate How these processes work in different cultural contexts. How photographs are treated in our work appears to be concerned with constituting persons and the photographic object in particular ways.

In Bristol in the UK, where we conducted ethnographic work networking from March - June 2002 (see appendix) photographs do indeed appear to reflect a sense of individual, temporal and moral unity. People feel obliged to negotiate around the sense of moral duty which appends to photographs, choosing whether to send a photograph in a calculating fashion, or let a photograph speak for itself as if with its own freedom. Framing a photograph is not a neutral activity, but is like making a social pact, largely, we suggest, because of the need within an English cultural context to maintain what may be called the integrity of the photograph, while also expressing social intentions. Intentions, however, are within England seen as important aspects not of objects but persons. Thus it is the variety of contexts within which photographs are found, framed, sorted and displayed that are a means for expressing multiple future social possibilities and aspects of the person. This parallels how Reed (2005) considers that weblogs index the persons who write them simultaneously as authors, subjects and audience. Although these artefacts are surrounded by the lingering suspicion that they contain a feeling or 'spirit', nonetheless their frames can be more animating than their spirit. Frames indicate appropriate periods of time to share. The sharing may never actually happen but the sense of goodness or appropriateness in the intention may be more important than exchange practices, and it is often practices of sorting and framing, more than sharing their content, which 
prove to be most closely connected to the sense of appropriateness. In Bristol, in the predominantly middle-class homes with whom we worked, it is the context, not the image itself, which "defines access to the past as a vision for the future" (Küchler 2002 p7). Domestic photographs are double materialisations. In their content they materialise experiences, while in their framing they comprise a representation of a moral community involved in exchanges. Rather than do a content analysis, which we leave for others, we focus on contextualising and framing.

By 'framing', we are not referring to any specific theoretical approach (eg. Goffman 1974), nor social perspective (Hirsch 1997), but to a set of practices we observed in people's homes. In short, people put photos in different places, including in frames, on boards, in books, and in envelopes, and it is these practices we refer to with the term framing. Framing illustrates how remembering is not only an abstract, internalised, passive process, but a socially creative act which happens in interaction with the external, material world.

As a brief illustration, there is a profound difference between getting a picture by e-mail, and being given the same picture in a thick wooden frame. The photo itself may seem pre-eminently rooted in time, and say something about a relationship by reference to the past, but in fact its frame can say more about the relationship than the photo. Consider Hugh, who is a retired engineer. In his home, on the bookshelves, are a number of photographs in cardboard frames (see Fig 1). Before even talking with Hugh, it is evident from the pictures that he is a grandfather. But we know more than this, because the frames are of a characteristic type for standard school pictures, which schools deliver to parents. We know immediately, without thinking, that Hugh has been sent these pictures by family. The frames indicate that he is a loved grandfather. The picture may contain a moment in time, a memory, an iconic representation, but the surround of the photograph tells us about the social dimensions to it, its transmission, and Hugh's future. 


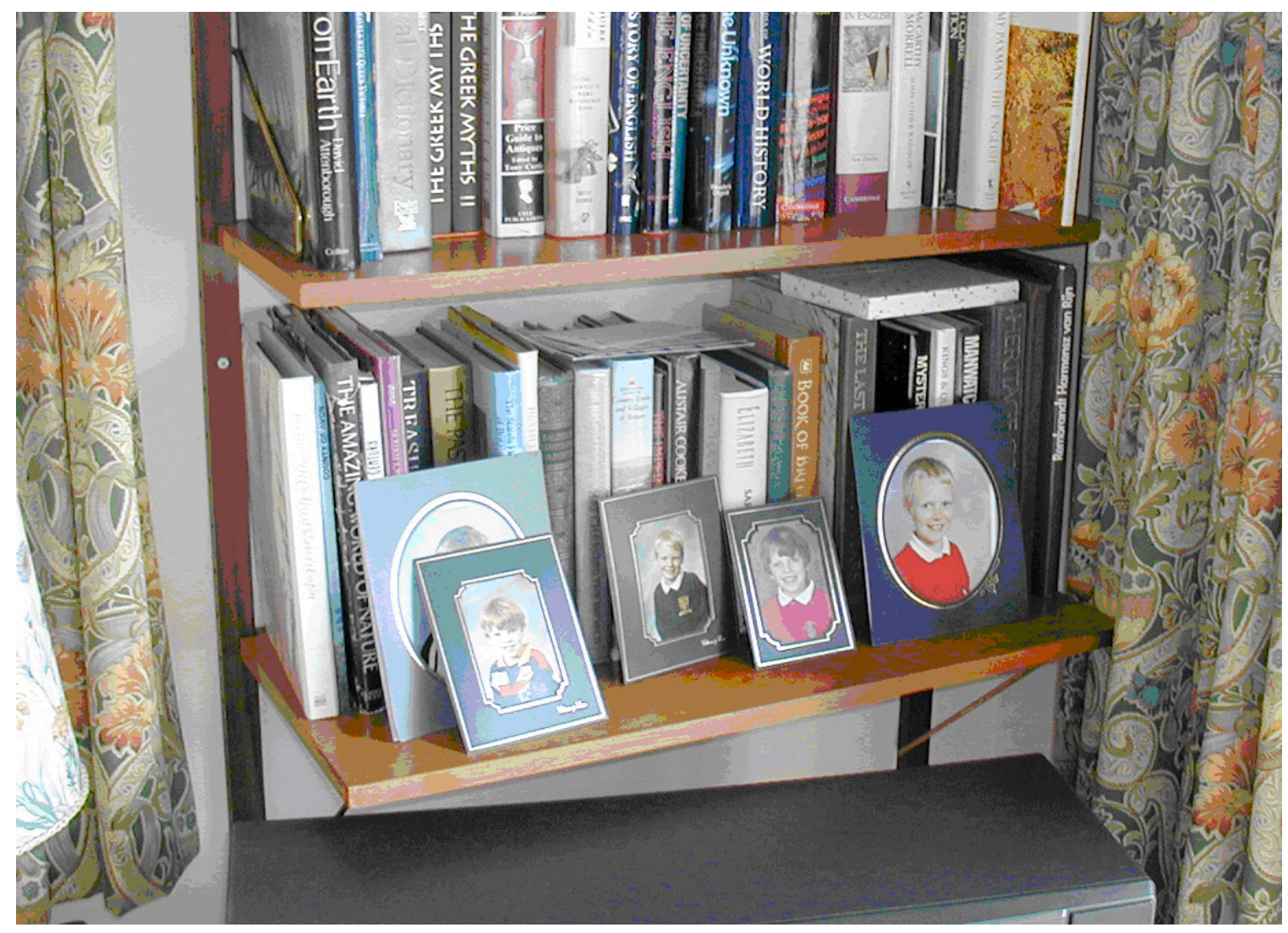

Fig. 1 The framing of photographs can tell us about relationships.

There are four sections to the paper. We first discuss what we mean when we say family photographs demand to be treated right: they are associated with a loose sense that it is morally correct to give them, and keep memory in circulation. Secondly, we outline a range of ways in which photographs are consumed, and the social and temporal mapping which these modes of consumption embody. Continuous sharing and sorting processes result in loose patternings, such that the framing of photographs in the home acts as a flag of collective good intentions. We thirdly discuss a particular case-study of several generations in one family, before rounding off the paper with some conclusions on the implications of this work for what remembering is and for what the person is in Bristol. 


\section{The Impulse to Share}

Concomitant to the construction of the photographic as an iconic record of a particularised moment of memory, is a physical context which represents a future of gift-like relations. Photographs participate in relationships and exchanges. They exist like pebbles within the current of a stream: there seems to be a pressure to keep them moving, to organise them, to use them somehow; most importantly, keeping them available for circulation. Among the nine homes with whom we have worked, "sharing" is the word commonly used to describe social activities around photographs. It may describe a number of assorted practices, as it is an inclusive term which collapses distinctions between the visual and practical (seeing photos and doing with photos). Sharing photographs is personal. It can be a difficult-to-refuse imposition, because it is much more than just showing images, but detailed memories and experiences too which the wrong person could easily find boring. Avidly sending reprints to an acquaintance you don't know so well can be a social faux-pas, as can not displaying a framed portrait you've been given, or forgetting to show photos to people you shared an experience with. Particular memories are appropriate for particular people, and people commonly characterise relationships when talking about particular photographs. So photographs are carefully selected, sorted and organised, and the showing of a picture is often the culmination of a much longer labour process making photographs fit to be seen. In short, more work goes in to making photos appropriate for sharing than in sharing itself.

In some cases, showing actually is a part of the organising process, and it is unclear whether looking at the pictures is primarily to share them or to work out what they are. In working at framing images, people are working at the contradictions of whether remembering with an image will be temporary and transient, or longer-term. Neil gives a good example of this, as he has a very loose, immediate approach to photography. He is a student whose social world is divided between a group of informal friends and his family. Among his friends, showing pictures probably just means passing round pictures from the envelope at the pub. As they socialise frequently together, everyone will be familiar with the events and people in the pictures: 
(Neil:) "We do (share them) when people first get them developed and we might go to the pub and just show them around, but usually we don't swap otherwise really. (You show them just the once?) Yes because we talk about photos and we might say 'oh, I've got a photo of you doing this', and they say 'oh, have you, I haven't seen that one'."

In this situation, there is no obligation to look through the whole set of pictures, nor any particular need to send any pictures, or reproduce any. Neil's presumption is that the group had the same experiences, so each picture probably has a personal link to the others. No strangers here. There is no risk of imposing with memories, nor any need to dwell on them for long. A lot of effort is put into making this group an ongoing one, meeting regularly.

At the other end of the scale from Neil's group is the display of pre-organised pictures, which may be shown to people who are less close, less personal. Albums can fall into this category - shown, for example, to friends who visit once a year or so. Most photographs when shown come between these two extremes. There can be a tension between the risk of imposing, and of failing to share. It is not the case that if a picture has a link to a person, for example is a picture of them, that you automatically show the picture to them. Ruth, a young mother who works in a book shop, showed us some pictures of a family occasion, with her brother in them. We asked whether she would show them to her brother, but she responded: "Not my brother. I'm not very close to my brother really. Immediate family and a few friends." Closeness negates some of the tensions. In most cases, it is a matter of negotiation and evaluation. She continued:

(Ruth:) “I do show them to other people if they're interested. There's one friend particularly who's quite into photography and is not bored by other people's photographs. We like looking at other people's photographs but not everybody is like that." 
Ruth produces albums which undoubtedly have the stamp of her personality, the captions written in her handwriting, but which are not unnecessarily fancy, framed or calculated. The fashion in which she conducts this negotiation says as much about her as the pictures do. She does not want to impose, and sharing photographic memories can definitely be an imposition. Ruth also occasionally gives or sends photos. In one instance, where the people shared the experience with her (much as Neil's group of friends above), she described this as "pooling" or "swapping around":

(Ruth:) "Well we were on holiday with a friend last year and I took some photos and I did send her one that we took at the time. This holiday we went with my mum and my sister and my niece and I think we pooled, we swapped around, I did some for them and they did some for me that they'd taken."

This instance is clearly very undefined, a form of sharing which is based on the group. There appears to be a sense of sameness and equality which is created by the arrangement. The 'swapping' is about instantaneity, with no time delay between the giving and receiving a picture. In other instances, Ruth sends individual pictures. In that case, the risk of imposing is greater, especially by sending something that has too much of oneself in it. One has to be careful to send the right pictures to the right people:

(Anthropologist:) "Who wants to receive photos?"

(Ruth:) "Well certain close friends who are interested enough in the children more than us to see what they look like now if they haven't seen them for three or four years. (So those are people who are relatives?) No not relatives, friends. We've got some friends who live in Cambridgeshire and we haven't seen them for about three years so we've sent them one and they've sent us one of their newest little girl. (But you'd be more inclined to send a photo of the kids than of yourself?) Yes, what do they want a photo of me for? If it was a nice one of all four of us together - like that one on the piano which is really nice, I would be inclined to send that perhaps to my mother, it's the kind of thing mothers like having." 
This is not a situation in which Ruth and the recipients have both experienced what's in the picture. They are friends, sharing some past memories, and the broadly common experience of having a daughter. The sender and recipient share a likeness, and exchange photographs representing similar, but not the same, experience.

In some situations, a photograph is sent which may provoke a specific response. The best example of this is Richard and Teresa, who send a picture of themselves and their family as a broadly annual event, to Christian friends. For Richard and Teresa, remembering in absence is linked to prayer. They would like to be prayed for, they need to be prayed for, and they pray reciprocally for other people. The photographs they send have fridge magnets stuck on the back, to deliberately create things which will remind people to pray, and remind people that they are being prayed for:

(Richard:) "We buy it from the States, an adhesive magnetic strip so we cut a bit off and stick it on the back of the card and then people can stick it on their fridge. I suppose the other thing being in the mission world we want people to keep being reminded of the people who pray for us, so stick it on the fridge and we're always on view."

These photographs are therefore quite specific in their link to a particular community, defined in terms of religion, family type, and national associations; and they are capable of building a strong community engaged in constant reciprocal exchanges across large distances through prayer; the photographs do this through their ability to give a presence to people who are absent.

We wish to emphasise the recurrence in different ways in different homes of one theme. Going through and sharing photographs, while not obligatory, is ascribed a positive social value. One informant said that he went through old photos because he'd invited us around: "In fact, talking about having to go through and sort out and chuck a lot away - well, I did that yesterday, hundreds of them." His wife added, "See - you've had a good effect!" This goodness thus applies not only to the giving and receiving of appropriate photos, but especially the prior process of sorting and ascribing photographs. The feeling 
parallels the sense of renovation other anthropologists have observed regarding passing on possessions when moving home (Marcoux 2001) or re-organising furniture (Garvey 2001). Organising photographs, framing them, consuming them, and (after a period of time) disposing of a proportion of old photographs is seen as a good thing. Sorting and sharing your memories is like accurately hitting a social target.

\section{How Framing Memories Constructs the Community of Home}

In practice, people do not necessarily share all their photos. Yet when we consider the material culture of ways in which they are framed and consumed in the home, the intention to share appropriately is concomitant with the context where they are found. It is not possible to produce a definitive patterning for

photo consumption. Every photo is subtly different. Among the print photographs we were shown, we perceived four overlapping forms of framing - ways of consuming photos - Disposable Photos, the Rogues Gallery, Albums, and Framed Photos.

Disposable Photos comprise what you might call the raw stuff of memory. These are typically the disorganised masses of photographs which lie around the home. The name comes from one of our informants, Rich, who employed a digital camera:

(Anthropologist:) “What photos do you take?”

(Richard:) "Mostly disposable photos if that makes sense. We do a lot of puppetry so when we went on puppet courses and things like that we quite often shoot off half a memory cartridge of all their props because there's a lot of sharing and people don't like you seeing how they do things, it's much easier just to photograph things close up."

Rich does Christian missionary work using puppetry, and consequently is always on the look-out for new, catchy visual techniques. He winds up with a lot of photographs. They are 'disposable' in the sense that he does not need them, but he does not actually dispose of them. Most photographs are of this order, a part of 
the raw stuff of the home in Bristol. There is no particular place to put them, no context to which they strictly belong. There are only places to which they do not belong, and have been moved out of. Loose photos lie in kitchen drawers, left there, although no-one remembers how they got there. Probably a photograph was on the table or work surface and, since it did not belong there, was tidied away. There will probably not be a shoebox of photos visible on a living room shelf; but there may be one in a cupboard, or at the top out of sight. Disposable Photos are not really 'kept' by people, so much as 'not disposed of', shuffled from box to box, relative to relative, from garage to attic to under-the-bed.

We would not argue that these images have a definite function or reason for being there. Very often, they are the pictures which capture memories least of all. Their social value lies in their potential for memory, not realised in the present. Culturally, they are of prime importance by way of contrast to more significant photographs. When placed against the background noise of a thousand loose images, other types of photograph are much more obviously valuable. If we draw on Stewart's work on the memento, we can say that Disposable Photos are potential mementoes in which the photographic thing has not yet superceded the experience.

The second form of photograph in the home is the Rogues' Gallery (Fig 2). This is the term used dismissively by Jason, when asked about the notice board at the bottom of the stairs: "There's the Rogues' Gallery in the hall at the bottom of the stairs," he said, "which is some of the family, and that gets updated from time to time." This cork board has a range of family photographs pinned to it, taken at different times and in different places. Many homes have a location like this. It does not have to be a cork board or even dedicated to photos. It could be the fridge door. It could be that the pictures sit on a kitchen board alongside unpaid bills, letters about school open days, and pamphlets for local takeaways. 


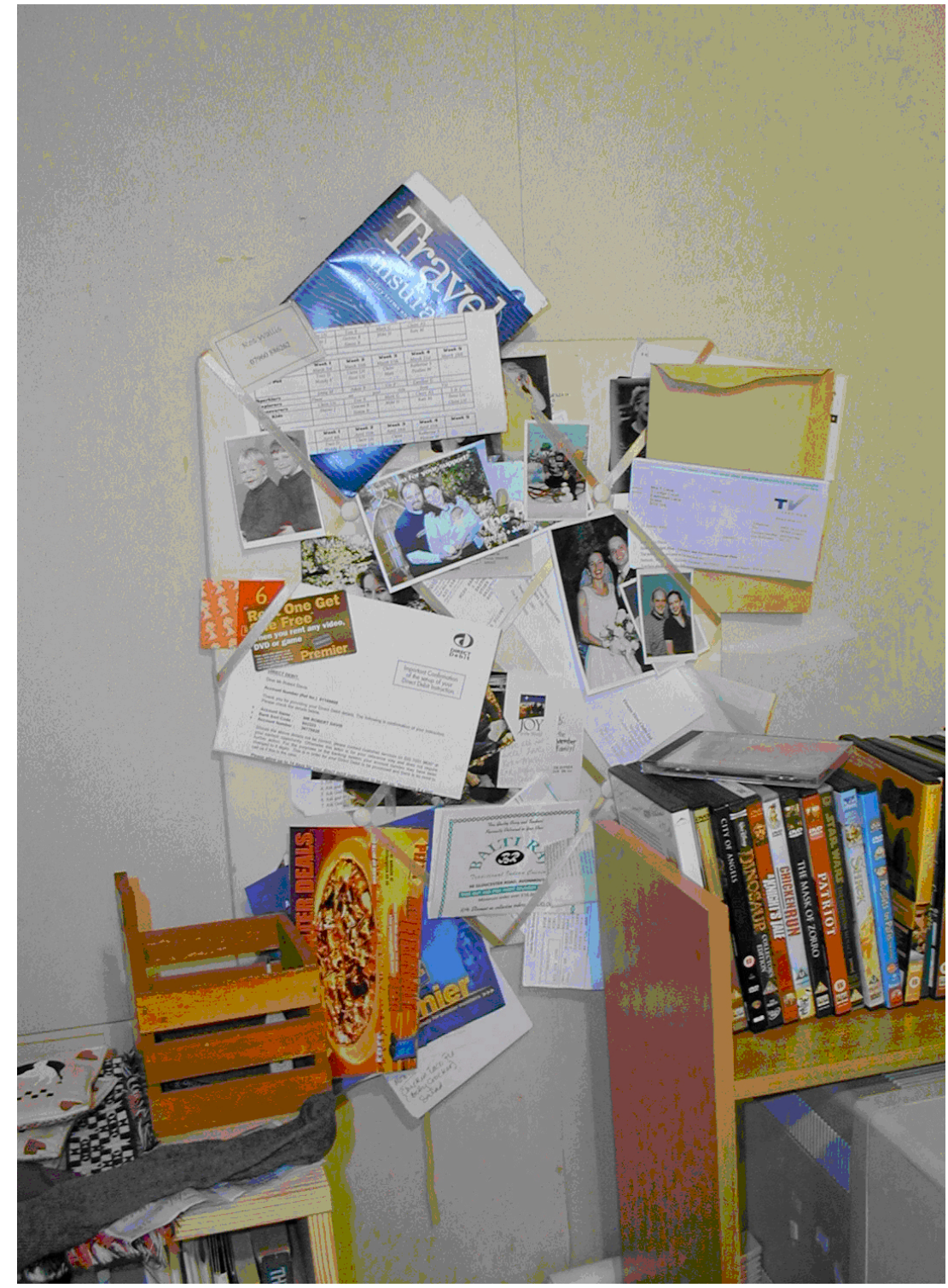

Fig. 2: A Rogues' Gallery, displaying friends' photos, pizza delivery menus and details of school open-days.

The Rogues' Gallery is treated with characteristic informality, though some are more formal than others. The pictures are loose, often pierced with many pins, often deliberately placed at a jaunty angle with calculated casuality. Any member of the family can move these pictures around, although one is likely to take more interest. They are located in many places, but rarely comprise a focus of attention. Locations we found included one at the bottom of the stairs, two on the hall wall just outside the kitchen, another on the fridge door, another using the kitchen notice board; transient locations. Other such boards also exist on the walls of teenagers' bedrooms. The images are not sacred or inviolable. One picture of a 
relative may become tatty, and be replaced by another more recent one. The board represents a particular periodicity, meaning a time-frame relating to action. Jason talks of pictures being replaced 'from time to time'. Likewise, the bills and takeaway menus pinned up in the kitchen are paper objects placed in view in order to stimulate action of a periodic type; and Rogues' Gallery photos seem to naturally assume a position here, provoking remembering from time to time.

Many of the pictures are not actually taken by people in the home. If you are sent a Christmas Card with a picture of the family inside, the appropriate place to put it may be a Rogues Gallery. Perhaps a year or two later, another picture arrives, and replaces the first. The latest picture of grandchildren abroad may be there, showing how they've grown. In this fashion, the gallery often has an 'external' focus, that is external to the household, and a content which is iconic and representative. It often has an explicit 'memory' function, which can be mutually agreed with outside people. Thus Rich, being a Christian, sends out a family photo annually so that people can remember them and pray for them. He employs this form of photograph as a technology to stimulate other people's remembering. The Rogues Gallery is not only about a form of memory where a person has an experience, takes a picture and remembers it. It is a facility which is explicitly set up for trafficking in photographic memories.

The third form of photograph framing is the Album (Fig 3). Albums show great variety in how they are made and what is in them, but there are some generalities. They are often located on shelves in the living room, but may be up in the bedroom if they are not for broad social exposure, or be moved into storage as they get older. Making Albums involves work and a sense of fixity, created with the deliberate intention of long-term future remembering. Unlike the Rogues Gallery, they are explicitly about preserving and keeping photos. One person is generally in charge of an Album: it is possible to talk about 'my album(s)'. What this means is that not only do individuals in the home have Albums of their own, but that if there happen to be Family Albums, these may come under the curatorship of one person. In the families we visited, the curator was usually the woman of the house. Her personality often emerges through how Albums look, the choices made about presentation, annotation, the money spent, where they are kept, and 
who can look at them. Albums can be looked at, but changing them requires her permission. Some of our informants produced organised, crafted albums, as a hobby. Ruth meanwhile gets cheap scrapbooks at the newsagent and glues the pictures in, then separates them into albums the children can look at (on a shelf in the living room) and those she wants to keep pristine for guests (in the bedroom). Neil's mother uses Albums with slip-in cellophane pockets, so that everyone in the house can slip their pictures into it with minimal work.

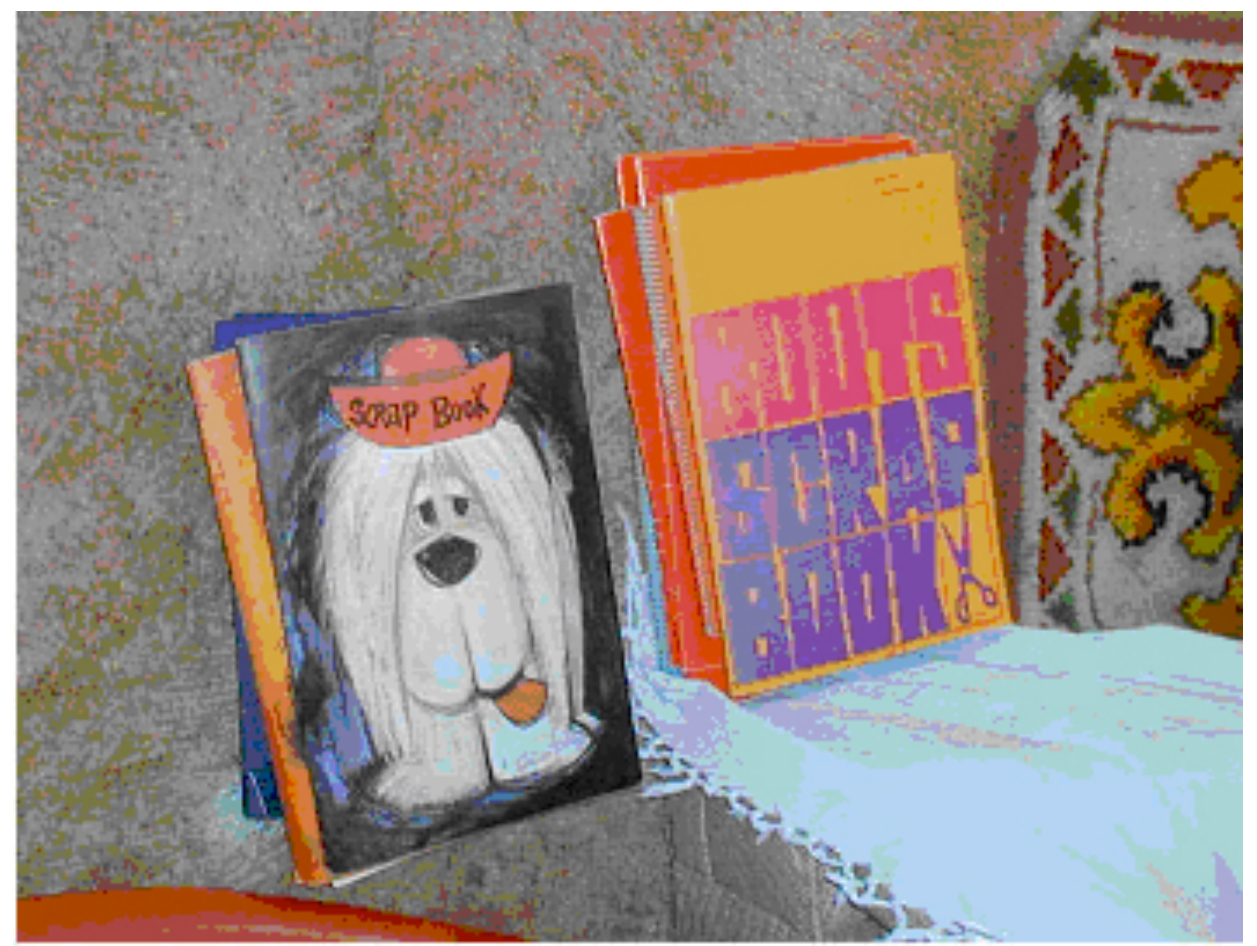

Fig 3. Albums. The albums here are scrap books from the newsagents. The photos are glued in with captions written alongside.

Albums link to memory in a particular fashion. They enable a type of remembering which is very close to the original moment when photos come back from the developers. While Rogues' Galleries and Framed pictures assume a property of iconic representation (that is, the one picture stands for a person or event), in Albums memory is materialised through co-location of images. A sequence represents a holiday, a walk, a birthday, rather than one event. An Album materialises the chains of memory from a particular year, the memory running through the Album in currents rather than dislocated moments. 
The fourth type of photo consumption is through Framed Photos (Fig 4), which in many cases assume a value wholly transformed from the loose Disposable Photos. A framed picture on the wall, particularly a portrait, has been marked out as having a very visible personal value, and often denotes blood-relatedness as it is noticeable that such images are almost exclusively of family and affines. A great deal of effort can be put into finding the right kind of frame for a picture. Sometimes, a frame fits in with the decor of the room so that it makes the photograph physically a part of the house. At other times, the frame relates to the kind of photograph it is, like the stereotypical ancestral picture with a heavy silvered frame. Framed photographs are co-located with certain types of objects - ornaments, or sometimes trophies. If a family has children, pictures of the kids may be set alongside school trophies. These trophies can again be seen as a particular kind of construction of time, which is personal and developmental. A trophy for sports is not a periodic reminder - 'I must remember to do sports' - like the swimming-pool schedule pinned on a Rogues' Gallery kitchen board. It is rather a marker of time in the sense of achieving a state which cannot be taken away from you, and is developmental. Although framed photos might appear to be ancestral in their ultimate form (see Ruby 1995; in parts of Europe, photographs are even found upon gravestones), they are still future-oriented. Older people have more photos, and there are more photos of younger than older people. The stereotype may be remembering ancestors, but the reality is the old remembering the young, by producing images of the future.

If we consider Stewart's work on mementoes, we can say that framed pictures have fully replaced the original experience or person they represent. Their manifestation as mementoes corresponds with their development as possessing a strong, materialised presence. They no longer represent time as moments, but in a more extended form. Neil has a particular picture of his girlfriend from on holiday: "she cut that one out for me and put it in like a heart-shaped thing." When he looks at it, he does not remember the holiday, or his girlfriend at a particular moment in time. He remembers her in general. The portrait presences her absence. To a certain extent, he has not even chosen the picture, although he likes it. He has no choice over the frame, and even seems a little equivocal in his non-committal, if precise, description of it. 


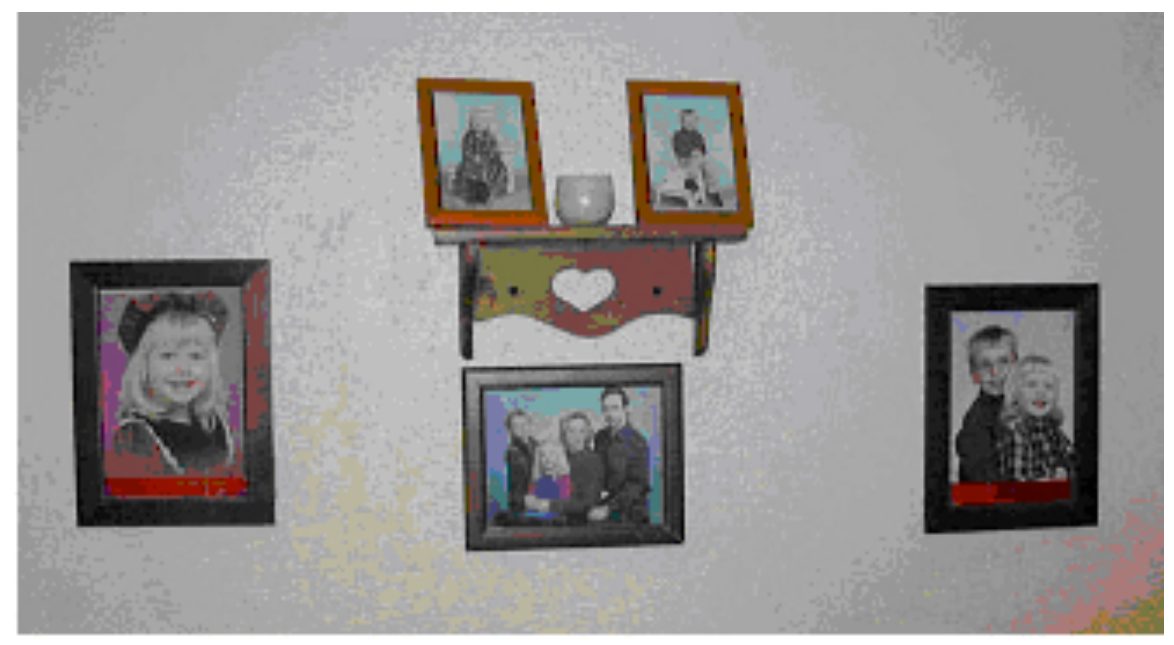

Fig 4. Framed photos. The visible images here overlay previous photos, year by year, so the whole embodies the children's and family's development.

We have presented these four ways of consuming photographs in a particular order which suggests increasing degrees of social formality and authority, increasing degrees of visibility to outsiders, and ever longer durations of time stretching into the future. Disposable pictures are fragmented moments of memory. Pictures on the Rogues Gallery epitomise events, places, or people on a 'from time to time' basis. Albums extend events into biographies, holidays, entire seasons. Framed photographs have rendered memory a part of history itself. The past, and the intention to remember or share in future, are corepresented. The different types of photograph thus come to map out not individual memories held in the mind, but a sort of social world of the home, constituted of shared memories and intentions to remember which have been made part of the physical fabric of the home. Photos of family members are in certain locations. Photos of friends are elsewhere, a little less formal. Somewhere are the pictures of others, fleeting figures in the life of the family, memories kept but rarely on view. In this way, the categories of photograph-framing have broad parallels with categories of people.

Once memory is materialised, it can be arranged in space. As the examples above illustrate, material memory is fashioned around the home into an interconnecting architecture. Some photographs are visible, while others are deliberately out of sight, and responsibility for these things is mutually and 
implicitly understood. Memory in the home can be a product of the work of the whole family, but often one person is the architect of memory, the person who takes physical charge of memory artefacts. Other people may join in, such that work is arranged as collaborative, although someone still has to set up the collaborative situation.

\section{What are Intentions and Why are they Good?}

There is therefore in these families a persistent future-oriented impulse to frame (in the sense of to materially contextualise) photographs; and this impulse is accompanied by careful handling of the feeling of social obligation which accompanies the sharing of photographs. Discussing the relevance of these observations to anthropology will take careful handling, as they evoke many themes, from gifts to memory to technology and art. The ethnography resonates with one of the longest-standing ethnographic currents within anthropology, looking at created artefacts from Melanesia and Polynesia, which likewise combine

roles as gifts (Mauss 2002), as visual art (Gell 1998), and as vehicles of memory (Küchler 2002). In this work, the common ground between these themes is found to be the way that material objects establish a dialogue with personhood (Strathern 1999), and this might be done with the content or with the frame of an image.

The investigation of a sense of duty goes back to Durkheim's concern with social order. Wherever there is a feel of resistance to individual choice, Durkheim (1972 p97) perceived evidence of social facts, the making manifest of society. For him, people experienced society as something larger and superior to themselves, and might be manifested in religious objects, citing the Yolngu art of Northern Australia (1972 p227) as one example. By contrast, for Durkheim's pupil Mauss (2002), the motivating force in objects might not be their manifestations of the collective, but as physical extensions of the person. In this sense, photographs of people appear to be the perfect Maussian gifts. The four kinds of framing we describe thus evoke the appearance of a gift economy of memory, spheres of increasingly exclusive reciprocal exchange (Bohannon 1955, MacCormack 1976). 
Nonetheless people do not actually give and receive photos in such a regularized, structured fashion as the patterning would suggest. In other words, there is the representation of an economy of exchanges, not the practice of one. The reality is closer to Moore's comment that the "organisation of space is not just a reflection of a set of social and economic relations; rather, it is a product, through practice, of individuals' images of those relations" (1986 p128). Moore argues that space becomes a collective medium through which actors are able to implement a social "strategy" or "orientation in the world" (p128) to address particular social stresses. Gudeman's (2001) approach tallies with Moore, commenting that the community precedes exchange, not vice-versa: "Nothing mystical, no sacred force in the gift causes it to be given, received and returned; the gift is a gesture of commensality not commensuration" (p92). He sees exchange as being motivated by "goodness" (p46), meaning to flourish or live well in an Aristotelean sense. Following this argument, the way photographs are framed in Bristol is not about the apparently selfevident fact that photographs seem irretrievably linked to persons such that their personality necessitates sharing, but rather about the way the physical surroundings of photographs manifest community, moral goodness, and intentions.

The most recent re-interpretation of Maussian approaches (Gell 1998) locates art as culturallyspecific ways of materialising networks of social efficacy or agency, and thus returns to the fundamental issue of the encounter with an impulse around photographs. This work is revealing of the particular English understandings of the person and agency which are at work in the way that photographs are being framed. We use the cultural referent "English" here because we are drawing on Strathern's work on English culture as a subset of what she calls "Euro-American" culture. In fact, two of our informants would describe themselves as American, and one as Welsh, but all are living in the cultural context of a city in England. Strathern (1999) writes in a commentary on Gell:

"As far as efficacy on others is concerned, one may thus see an art object in the same way as one may see a person. It embodies capacities. Euro-Americans often think agency inappropriately personified when it is applied to inanimate entities, but that is because they link agency to will or intention.” (1999 p17) 
Several points need careful clarification at this point. First, agency (as the extended person) and intention are not necessarily linked together, but they are linked here. Intention acquires particular significance within what Strathern calls "Euro-American" cultures. Second, the act of remembering is linked in the English context with photographic records, seen as "accurate" reflections of the world, but any object can construct ways of remembering. Küchler discusses remembering around Melanesian Malanggan carvings which "define their access to the past as a vision for the future in forever new and hope-inspiring ways" (2002 p7). Third, however, art and photography are seen as different things in England. While it is possible for an English person to look at a carved effigy of a person from Melanesia and believe it (perhaps mistakenly) to stand for that person, a photographic effigy is not seen this way, it is more a reflection, supposed to be self-evidently an inanimate object. To distinguish between frame and photograph is more than to distinguish the delineation of a space from the filling of that space with content (Gombrich 1984). It is rather to distinguish the relationship of the image's creator to its recipient, from the image's relationship to its subject (Reed 2005, Gell 1998). The former relationship becomes characterised by intentions, while the latter denotes the construction of the photographed world as given, a 'natural' backdrop to human relations. Both Strathern (1992) and Tyler (2003) consider that this conception, of nature being a backdrop to authentic belonging, is an English classed phenomenon, and our predominantly middle-class informants follow the pattern they observe.

With these considerations in mind, the significance of framing and expressing intention around the facticity of photographs should become more clear as an important manifestation of ways of being a person within families in England. Strathern (1992) suggests that the first fact of English kinship is individuality of persons, and one quality of these persons is will or intention. Intention here becomes not a function of psychology which precedes action, but a cultural construction. The sorting and framing of photographs marking the intention to remember to share does not always result in the action of sharing. Rather, framing provides an important means to socially express the quality of having intentions, in a situation where within an English cultural context the photograph is not permitted to be an extension of the person. In this sense, 
the framing manifests a sense of community and moral goodness as it links to the heart of ways of constructing kinship and home.

By contrast with these notions of the person in Bristol, Pinney (1997b) discusses photographic portraiture in India, which displays marked preference for images with multiple perspectives and poses by the subject within one image. He argues that this links not only to conceptions of multiple persons, but a faith in the moral opacity of the individual, whose moral interior, it is locally believed, cannot necessarily be read from the exterior. Portrait photographers therefore can paint photographs, change clothes, add multiple images unhindered by the idea that the appearance of the portrait should be anchored to an individual's internal moral character. By contrast, he suggests, citing Barthes, a "western portrait tradition" (p94) exists within which expectations of photography may involve looking not only for a true image but a "just image" (p94). In Bristol, such radical manipulations of the image as in India are not permitted. Instead, very many images are 'captured', continually selected and circulated by means of multiple ways of framing and contextualisation. We earlier mentioned how Ruth, in talking about what pictures she might share, indicated a family group photo which happened to be on the piano, saying "I would be inclined to send that perhaps to my mother, it's the kind of thing mothers like having." There always seems to be a photograph around appropriate to send to someone particular. Yet what is the determinant of the "kind of thing" which this is? Is it the subject, or the person who took it and what they intended, or the frame, or the person to whom it is destined (the category of things liked by mothers)? The point is that the sending to Ruth's mother is not pre-ordained, but that out of hundreds of given family portraits, the processes of selection, relocation to a privileged central position in the home, and framing, have created a photographic artefact which expresses possibilities, the appropriateness of being a photograph for a mother. The creation of what it means to be a mother takes place within this network of intentions, and the personality is in the framing. In India, the image itself might rather be changed to assist in constructing appropriate relationships.

In framing activities, of the banal kind which we have defined, photographs become a taken-forgranted part of the home. The artefacts create a sense of home and create what it means to be a person. 
They map out in space channels of sharing and gradations of relationship, doing so with reference to closeness to the household and privileging those in the home above others. A moral home is both independent and interacts with others (imagine a home where all the pictures are of people who live there and no-one else, as if they never mean to remember anyone from other homes). Photographs indicate activity in wider social networks, and the fulfilment of social responsibilities. In this sense, the origins, progress and development of the home and its members are indicated on its walls. Long-term moral intentions are evident. The motivation behind photographic framing practices does not only lie in the recapturing of the past, but the preservation and realisation of possibilities for the future.

\section{Photographs Across Three Generations of One Family}

Every home is casual but different and personal with its photographs. We have examined how photographs are framed from many perspectives, and will now illustrate how all these themes integrate across one family. The apparently casual use of photographs in the descriptions which follow evokes all the analyses we have discussed so far. In spite of the unconscious informality, a sense of obligation to treat and share photos right is pervasive, and the reader should detect the deeply good, unspoken, collective feelings and intentions which underlie these paper images amid the chaos of everyday life.

We first met Jason through a group devoted to listening to music. He was enthusiastic about the idea of talking about photos and music, sensing an opportunity for a family get-together. His wife Brenda had a stroke a year or two before we talked, and so he takes every such opportunity. He organised an evening at his house when his step-daughter Joan and her husband Brian came around with their albums. We asked if any younger family members might be interested, so Joan broached it with two nephews at another get-together the following week. We then visited Neil, who is a 21-year old student, at his home, and also later on met his girlfriend Kathy. In all, we therefore met three generations of relatives; a couple in their seventies (Jason and Brenda), one in their late fifties (Joan and Brian), and one around twenty (Neil and Kathy). The extended family around Bristol seems pretty active. It was always somebody's birthday 
next week, or else there had just been a christening. At these kind of casual events, the latest set of photos is often produced, and occasionally they get out albums. Copies of photos may make it on to the Rogue's Gallery in Jason and Brenda's hall, or up onto the board that Joan's daughter has in her bedroom, or into the communal album which Neil's mother keeps. Somehow casually, everyone sees every picture.

(Anthropologist:) "Do you ever show your photos to your mother and Jason?"

(Joan:) “Oh yes, they've seen every single photo I think we've ever taken, as interested grandparents." (Anthropologist:) "Just because they'd be interested?"

(Joan:) “Yes, I think so."

(Jason:) “Yes, glad you've been on holiday and you're telling us about it, and showing us these, or events where we're present, parties or family get-togethers."

(Joan:) "We have a lot of family get-togethers."

Jason and Brenda's home is a terraced house in North Bristol. Apart from the Rogues' Gallery in the hall, in the back room where they spend most of their time a cluster of framed photographs stands on a coffee table, near the TV and Brenda's easy chair. As guests however, we are ushered into the front room, where the framed photos are a little more formal, not in portable standing frames but hanging up on either side of the fireplace. In our discussions, John seems relatively preoccupied with Brenda's stroke. Among the pictures he chooses as his favourites is a picture of her on a trip which they made to Chew Valley Lake a couple of years ago. The woman in the photograph looks very different from Brenda now, with one side of her face very stiff, her wispy white hair, and her tortuous difficulty walking. Jason seems aware that he wishes to capture memories as accurately as possible because of the fleeting nature of time:

(Jason:) "As one gets older there tends to be, not nostalgia exactly, it's a realisation that once that photo of a person is taken they're never going to be the same again, not even the next day, so you're capturing moments in time and I think as one gets older that tends to have a bit more meaning." 
He likes his portrait photos to show people 'warts and all', and tells the story of how, when he was younger, he was in Germany, and sent a picture home to his girlfriend of the time. He found himself writing on it "it's not a very good one", and then realised he just wanted to provoke her into replying "yes it is", so he could feel good about himself. He didn't quite like that tendency in himself, to use a photo to oblige an appropriate response, so he prefers unadulterated pictures: "I think when we share things, there's always that bit where people say 'oh, don't look at that one', but if you've got some photographs that you've chosen at random from dozens, or hundreds, and put them together, they're all ones that I like for various reasons." During the conversation, Jason thus builds moral images around photographs, whose content can reflect a deeper truth or beauty. Perhaps his awareness of the life-affirming nature of photos is a result of the time he has had in retirement for reflection, or his spiritualist religious beliefs. Every photo is a good one. Yet when sharing photos, he feels he has to guard against using them for emotional manipulation. The sharing of images still means selectivity, even if all are good.

Joan and Brian are much busier than Jason and Brenda, especially Joan, but some similar themes are evident. They have a lot of photos, which they generally put in albums, although they haven't for a few years. They don't have so much time since Joan was promoted at work:

(Brian:) “We started with good intentions. We've got lots of photograph albums up on a high shelf, but we've got lots more of photographs that we've just collected from the photographer and have never bothered to file, and half of them need throwing away, and if we want to find something it would take hours and hours... Perhaps you've prompted me now to get around to filling some more albums and emptying our drawers of photographs."

There is too much to do. Yet the albums do get used, especially on occasions when people visit: "The children love going through, particularly if we have a visitor who hasn't seen them when they were younger, and they enjoy reminding themselves of friends who've moved away and such." The children 
also reorganise the albums, and have a right to images of themselves. When their daughter turned eighteen, she looted all the old pictures of her from the family albums for her own album, which she keeps up in her room. Two years after that, at her twentieth birthday, she decided she wanted a framed collage of photographs:

(Brian:) "When she was twenty-one, she wanted me to make a frame for her. So I made up a carved frame with her name at the top and twenty-one years around it, and she's filled it with all her favourite photographs."

(Joan:) “She's quite artistic, like Brian, so she will think about how to present it as well as not necessarily just choosing the ones she likes but what the presentation looks like, she's got various photographic montages in her bedroom, she did her first one when she was about fifteen, didn't she?" (Anthropologist:) "Where did she get the idea from?" (Joan:) "I don't know... we've never done it, maybe she got it from school possibly."

The way that Joan, Brian, Jason and Brenda organise and talk about their photographs is not very dissimilar, but Neil does things differently. He's a student. He still largely lives at home, and socialises with all his friends from school. Neil's initial presumption is that we are talking about photos of him and his mates, and he produces a mass of loose envelopes from drawers. He has a very momentary approach to the pictures. He doesn't frame or album them much and often uses a disposable camera. He and his friends once went through a phase of taking a disposable camera out around Bristol on a Friday night, and taking photos with whoever they met. One of the pictures he picks shows them with a wild-eyed hairy man, all sitting on a pavement, thumbs up to the camera. The man was a homeless guy they met begging on the street that night, who they felt needed a bit of cheering up. He seemed "really into it", Neil says.

As the conversation runs on, it emerges that there is a whole other set of photos which he has, or at least has access to, which he never thought to show us. These photos are less about events and more about people, and in a sense communal to the family, distributed around the home. They comprise family photos, 
and photos with his girlfriend Kathy. Neil's mother maintains some slip-in albums in the living room, and when we ask to borrow and copy a picture, Neil asks his mother's permission first. These family pictures are not really appropriate to show to friends without imposing:

(Neil:) "Yes. I just keep (them) in the lounge and they just come 'round and have a look whenever they like. That was my birthday I think. ” ...

(Anthropologist:) "So who do you show these albums to?"

(Neil:) "Well all our family when they come over really."

(Anthropologist:) "Not your friends?"

(Neil:) "No, they're not really interested. Only holiday photos, that's about it."

Unlike his grandfather Jason, Neil does not actually like going through old pictures which remind him of how he used to look. When we ask Neil about 'old photos', he understands these to be pictures from the early 1990s. He finds it disturbing to see himself looking so different, but keeps the pictures nonetheless. "Old photos, I've got baby ones and all that," he says, "I went through a stage when I used to look at them a lot... That sometimes is not a good idea-... I don't know, some photos, I wouldn't say sad, but it's just the past, isn't it? When you were a lot younger."

\section{Conclusions: A World of Good Intentions and Messy Memories}

In looking in our ethnography at the material culture around photographs in the home, we are taking a different perspective from many previous studies, and hoping to draw attention to an area which deserves more attention in the study of photographs.

Very many approaches to photography focus on the content of images as information, and in particular the idea of memory as the individual accessing the past. From this point of view, the relevance of the way photographs are framed is primarily practical, and as a form of storage. Many of the phenomena 
which we describe might from this perspective be ascribed to the difficult practicalities of everyday life in a world full of technology. Ever more photographs and images are made by families with their cameras, producing a spiralling, ever-expanding multitude of images filling the home, more than the mind can comfortably conceive. There are simply not enough hours in the day to sort these effectively, nor to maintain all the social contacts one would wish. There is not enough money to make all the prints one should share with others. From this point of view, the ways of framing photographs are a poor way of actually storing images of the past in a way that one may access, nor is it likely that one will ever manage to 'control' the photographs in the home.

We invite an alternative perspective, exploring what is being contextually expressed more than what is being controlled. The assorted ways of framing turn out to be a wonderful way of materialising intentions for the future. An infinitely subtle profusion of intentions may be expressed, distinguishing with some precision different periods of future time, and different relationships and types of person. From our perspective, the sense of what is happening with shoeboxes, albums, boards and frames begins to make sense. It draws on the particular cultural relevance of intentions and ways of materialising social capacities in an English context, as outlined by Strathern; and also maintains the claims to a moral 'truth' about the person which according to Pinney Western photographic genres are expected to manifest. This position arises from our observations about the way apparent patterns in framing arise. People are not designating an organized system, but responding to the appearance of photographs as objects which should be treated appropriately, as we outlined in our discussion of the impulse to share. This is done by appropriate contextualising, resulting in the four ways of framing we have described.

This approach has a number of implications. The act of remembering is commonly understood as occurring with an attitude of recovery from the past. This may be true in many instances, particularly if considering photographs as isolated objects. In our work, however, the act of remembering appears as a future-oriented, creative act, remembering to remember in future.

The ways in which photographs come to be framed in domestic contexts communicate constructions of temporality (isolated moments, from time to time, biography, history), and appear to 
reflect categories of people as kin and non-kin, friends and acquaintances, and people present or not present in the home.

The acts of looking, of sorting, and physically transmitting photographs are sometimes considered separately, and the act of looking considered to be primal for photographs; but in a very large proportion of the instances which we have investigated, looking, sorting and sharing are integrated into the same moment of activity. More evident work is conducted directed at sorting and framing than at looking. Sharing, as an activity, is not wholly democratic and liberated, but heavily proscribed by social requirements.

From a social perspective, this means that physically sorting and sharing photographs in a socially appropriate fashion may be the motivating factor behind photographic activity, more than looking at photographs. Remembering does not appear as an individual activity. The recurring theme of the cultural creation of goodness, and having good intentions, reflects the future creation of a moral household and community.

Photographs demand of us that they be treated right, not thrown away, maintaining themselves as a large floating reservoir of imagery and potentialised memory. The photographic artefact, comprising the image and however it is physically framed, create "distributed objects in time and space" (Gell 1998 p221). Just like trying to keep track of all your photos, it is difficult to try to explain all the themes which emerge from ethnographic data. The more threads we followed in our research, the more threads we discovered, and we have nonetheless tried to identify and explain the important ones. Framing, sharing and remembering are intertwined with emotional currents and a sense of living in a good way, and each of these threads is different for different people. In our research, they amount to a compulsive tapestry of good intentions.

\section{Acknowledgements and Methods}

The research for this study was conducted at and by Hewlett Packard Laboratories, Bristol, with Tony Clancy of Lancaster University, and comprised two stages as part of a broad study on memory and media. 
Rewriting was conducted with the assistance of a grant from the Irish Council for the Humanities and Social Sciences (IRCHSS). Many helpful comments were made by members of the Global Dinner Group, who know who they are. The broader study is reported in Frohlich (2004).

We spent a period of three months, from March-May 2002, conducting ethnographic fieldwork among families to talk about photos and music in their homes. Initial contact was with two interest groups, firstly a craft group involved in making photo albums as a hobby; and secondly a recorded music society, who meet weekly to listen to a music compilation which one member selects and presents. We networked onwards from these initial people to meet others with whom they share memories through photos or music, meeting nine households in all, criss-crossed by relationships involving the sharing of photographs. Families were primarily middle-class. This was not intended, but appears to have arisen from the practiceoriented definition of the field, focusing on the hobby-groups.

The work involved 13 individuals, including 5 couples (married or unmarried), profiled as follows:

\begin{tabular}{|ll|r|}
\hline Profile of Informants & & $n$ \\
\hline \multirow{3}{*}{ Total } & & 13 \\
Gender & Male & 6 \\
Age & Female & 7 \\
& $20-39$ & 6 \\
Social Class ${ }^{*}$ & $40-59$ & 2 \\
& $60+$ & 5 \\
& $A$ & 0 \\
& $B$ & 6 \\
& $C 1$ & 2 \\
& $C 2$ & 4 \\
& $D$ & 1 \\
& $E$ & 0 \\
\hline
\end{tabular}

* Social Class follows the Standard Occupational Classification format of 1990, used until recently in UK census surveys.

\section{References}


Bohannon, Paul. 1955. Some Principles of Exchange and Investment among the Tiv. American Anthropologist, 57: 60-70.

Bourdieu, Pierre. 1977. Outline of a Theory of Practice. Cambridge: Cambridge University Press.

Buchli, Victor \& Gavin Lucas. 2001. The Archaeology of the Contemporary Past. London: Routledge. Durkheim, Emile. 1972. Selected Writings, edited by Anthony Giddens. Cambridge: Cambridge University Press.

Edwards, Elizabeth. 2001. Raw Histories: Photographs, Anthropology and Museums. Oxford: Berg. Edwards, Elizabeth \& Janice Hart. 2004. Photographs Objects Histories: on the materiality of images. London: Routledge.

Forty, Adrian \& Küchler, Susanne. 1999. The Art of Forgetting. Oxford: Berg.

Frohlich, David. 2004. Audiophotography. London: Kluwer Academic Publishers.

Garvey, Pauline. 2001. Organised Disorder: Moving Furniture in Norwegian Homes. In Home Possessions: Material Culture Behind Closed Doors, edited by Danny Miller (Ed). Oxford: Berg. Gell, Alfred. 1998. Art and Agency: an anthropological theory. Oxford: Oxford University Press. ---. 1999 (1992). The Technology of Enchantment and the Enchantment of Technology. In The Art of Anthropology. Alfred Gell, 159-187. London: Athlone Press.

Goffman, Erving. 1974. Frame Analysis. New York: Harper.

Gombrich, Ernst. 1984. The Sense of Order: a study in the psychology of decorative art. London: Phaidon.

Gudeman, Stephen. 2001. The Anthropology of Economy. London: Blackwell. Hanganu, Gabriel. 2004. 'Photo-cross': the political and devotional lives of a Romanian Orthodox photograph. In Photographs Objects Histories: on the materiality of image, edited by Elizabeth Edwards and Janice Hart. London: Routledge.

Hirsch, Marianne. 1997. Family Frames: photography, narrative and postmemory. London: Harvard University Press.

Küchler, Susanne. 1999. Binding in the Pacific: Between Loops and Knots. Oceania, 69(3): 145-56. 
---. 2002. Malanggan: Art, Memory and Sacrifice. Oxford: Berg.

Kuhn, Annette. 1995. Family Secrets: Acts of Memory and Imagination. London: Verso.

MacCormack, Geoffrey. 1976. On Reciprocity. Man, 11(1): 89-103

Marcoux, Jean-Sebastien. The Casser-Maison Ritual: constructing the self by emptying the home.

Journal of Material Culture 6(2): 213-235.

McCracken, Grant. 1989. 'Homeyness'; a Cultural Account of One Constellation of Consumer Goods and

Meanings. Interpretive Consumer Research, edited by Elizabeth Hirschman, pp. 168-184. Provo, UT:

Association for Consumer Research.

Mauss, Marcel. 2002 (1950). The Gift: the Form and Reason for Exchange in Archaic Societies. London:

Routledge.

Miller, Daniel \& Don Slater. 2000. The Internet: an Ethnographic Approach. Oxford: Berg.

Miller, Daniel. 2001. Behind Closed Doors. In Home Possessions: Material Culture Behind Closed

Doors, edited by Daniel Miller, pp.1-22. Oxford: Berg.

Moore, Henrietta. 1996 (1986). Space, Text and Gender. London: The Guilford Press.

Pinney, Christopher. 1997a. Camera Indica: the Social Life of Indian Photographs. London: Reakton.

---. 1997b. Photographic portraiture in Central India in the 1980s and 1990s. In The Material Culture

Reader, edited by Victor Buchli, pp.87-103. Manchester: Manchester University Press.

Pinney, Christopher \& Nicolas Thomas. 2001. Beyond Aesthetics: Art and the Technologies of

Enchantment. Oxford: Berg.

Reed, Adam. 2005. 'My Blog is Me: Texts and Persons in UK Online Journal Culture (and

Anthropology). Ethnos 70(2): 220-242.

Ruby, Jay. 1995. Secure the Shadow. Cambridge, MA: MIT Press.

Sontag, Susan. 1977. On Photography. London: Penguin.

Stewart, Susan. 1984. On Longing: Narratives of the Miniature, the Gigantic, the Souvenir, the Collection. London: Duke University Press. 
Strathern, Marilyn. 1992. After Nature: English kinship in the late twentieth century. Cambridge:

Cambridge University Press.

---. 1999. Property, Substance and Effect: Anthropological Essays on Persons and Things. London: The Athlone Press.

Tyler, Katharine. 2003. The Racialised and Classed Constitution of English Village Life. Ethnos 68(3): $391-412$. 